\title{
Effect of Plasma Discharge on Epidermal Layer Structure in Pig Skin
}

\author{
Ahmad Guji Yahaya, ${ }^{a, *}$ Jaroslav Kristof, ${ }^{\mathrm{b}}$ Marius Blajan, ${ }^{\mathrm{b}}$ Fariha Mustafa, ${ }^{\mathrm{b}}$ \& \\ Kazuo Shimizu $u^{\mathrm{a}, \mathrm{b}, \mathrm{c}}$ \\ aGraduate School of Science and Technology, Shizuoka University, Japan; ' Graduate School of \\ Integrated Science and Technology, Shizuoka University, Japan; 'Organization for Innovation \\ and Social Collaboration, Shizuoka University Japan
}

*Address all correspondence to: Ahmad Guji Yahaya, Graduate School of Science and Technology, Shizuoka University, Japan; Tel.:/Fax: +81-53-478-1443, E-mail: Yahaya.ahmad.guji.19@shizuoka.ac.jp

\begin{abstract}
Plasma can efficiently inactivate microbial pathogens. Application of plasma on the skin can not only kill bacteria but also change the nature of skin. The influence of plasma jet treatment on the stratum corneum was investigated using the skin of a Yucatan micro pig. Microscopic observation of the histological skin section was used to characterize the etching effect of plasma jet depending on treatment time. Changes in lipid conformations were determined by the bandwidth and absorbance of the symmetric and asymmetric stretching of $\mathrm{CH}_{2}$ and $\mathrm{CH}_{3}$ bands and their ratios using ATR-FTIR spectroscopy. Plasma jet caused structural changes observed via an increase in bandwidth and a decrease in absorbance of the lipid vibrational bands. Plasma effects were saturated after 2 min of treatment. The influence of temperature and UV irradiation was also evaluated. The monitoring of plasma-treated skin demonstrated the temporal effect of changes caused by plasma.
\end{abstract}

KEY WORDS: FTIR, lipids, plasma jet, stratum corneum, skin treatment

\section{INTRODUCTION}

Plasma generates highly reactive species (ions, electrons, excited atoms, molecules, radicals, metastable states, UV radiation, and heat). ${ }^{1}$ Some of these species, particularly reactive nitrogen species (RNS), penetrate and dissolve in some tissues up to $1.25 \mathrm{~mm}$ thick. $^{2}$ If not carefully controlled, these species cause tissue damage ${ }^{3,4}$ in biomedical applications of plasma ${ }^{5}$ such as wound healing, skin treatments, ${ }^{6-9}$ transdermal drug delivery for pig and human skin, ${ }^{10-17}$ or sterilization. ${ }^{18,19}$ Except for sterilization of medical devices, it is also necessary to decontaminate human tissue such as hands or body parts prior to surgery or injection. Hand sanitizing by plasma and the plasma jet device has been investigated. ${ }^{20-22}$ However, application of plasma to the skin can not only kill bacteria but also cause some changes to the skin itself. Thus before application, it is crucial to evaluate possible effects of repetitive use because plasma can decrease skin thickness and also decrease the skin's barrier properties.

The epidermal layer of the skin is composed of a viable epidermis and the stratum corneum. ${ }^{23}$ The stratum corneum is formed by death cells in a lipid matrix. Death cells and lipids are the body's main barrier against foreign substances. ${ }^{24,25}$ They also exhibit a selective permeability and allow only relatively lipophilic compounds to diffuse into 
the lower layers. ${ }^{26}$ Choi et al. ${ }^{27}$ reported that plasma reduced the skin's barrier properties through reduction of E-cadherin expression; they were revived $3 \mathrm{~h}$ after plasma treatment. E-cadherin is a cell adhesion molecule that is very important in the formation of junctions to bind cells to each other. ${ }^{28}$ Lee et al.$^{29}$ compared argon and helium discharge; they found argon discharge to be more effective than helium discharge in E-cadherin regulation (decrease in the barrier function) because of higher density of reactive species. They also observed that ions played a key role in enhancing skin permeability. Argon discharge contains the most populated species: argon atoms, argon ions, and argon metastable states with impurities coming from atmospheric air.

Depending on the purpose and setup of the plasma application, etching on the skin surface and the grafting of lipids by air particles are possible results of bombardment by ions, followed by reaction with released oxygen, nitrogen, or hydrogen. Plasma can change the structure or chemical composition of the skin to enhance permeability. ${ }^{30}$ In this study, changes caused by plasma were observed using attenuated total reflectance Fourier transform infrared (ATR-FTIR) spectroscopy. Effects of treatment time, temperature, and radiation were evaluated along with posttreatment behavior. Structural changes in lipids was measured according to bandwidth and absorbance of symmetric and asymmetric stretching of $\mathrm{CH}_{2}$ and $\mathrm{CH}_{3}$ bands and their ratios. Histological observation of skin sections determinedthe skin-etching effect.

\section{EXPERIMENT}

This research focused only on the effect of plasma jet irradiation on the stratum corneum. Previously published papers ${ }^{31-33}$ confirmed that cold atmospheric pressure plasmas can cause internal skin changes. To characterize these effects, microscopic observation of histological skin sections was used to observe the etching effect of plasma jet depending on treatment time. Changes in lipid conformations were also observed via bandwidth, as were the absorbance of the symmetric and asymmetric stretching of $\mathrm{CH}_{2}$ and $\mathrm{CH}_{3}$ bands and their ratios using FTIR-ATR spectroscopy.

\section{A. Experimental Setup}

Plasma jet ${ }^{33}$ was generated using $99.99 \%$ pure argon gas (Fig. 1). The flow was set at $3 \mathrm{~L} / \mathrm{min}$ by a flow meter (Yamato). The discharge voltage was ignited at $4 \mathrm{kV}$ and at a frequency of $16 \mathrm{kHz}$ by a neon transformer (Model M-5, Alpha Neon). The distance between the skin samples and the outlet of the plasma jet was set at $2 \mathrm{~mm}$ via a grounded micrometric sample holder. The samples were isolated from the holder by a 30-mm-thick PVC isolator. Treatment time was set at 10-900 s (15 min). The effect of UV radiation was evaluated by use of a filter between the plasma jet and the sample. The temperature effect was tested using a hot air fan. The upper layer of the stratum corneum was analyzed using a diamond prism ATR-FTIR spectrometer (FT/IR 6300, Jasco, with PRO610P-S, ATR). The spectra were recorded at a resolution of $8 \mathrm{~cm}^{-1}$ and by accumulating 150 scans. 


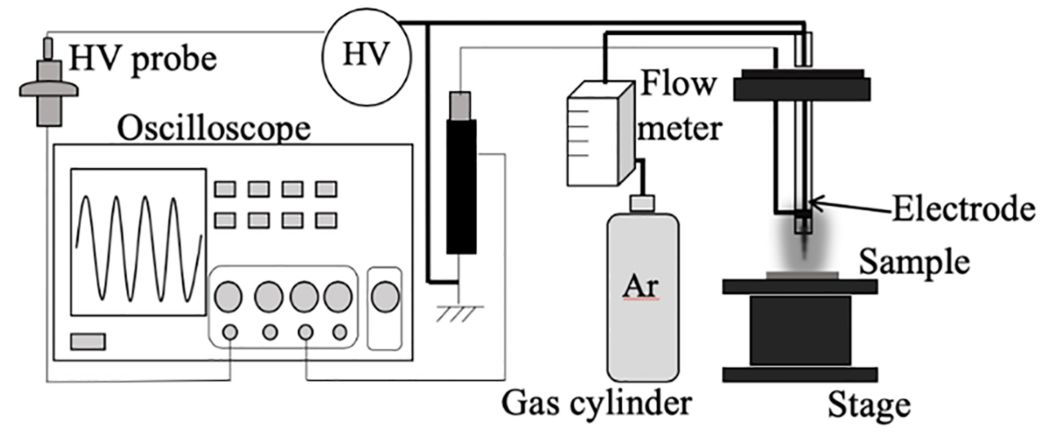

FIG. 1: Experimental setup for plasma jet

\section{B. Sample Preparation for ATR-FTIR Measurements}

Yucatan micropig skin, purchased from Charles River Japan was stored at $-20^{\circ} \mathrm{C}$ in a freezer before the ATR-FTIR experiment. After removing its fat layer, the skin was cut and soaked at $4{ }^{\circ} \mathrm{C}$ for $3 \mathrm{~h}$ in phosphate buffered saline (PBS). After a water bath at $60^{\circ} \mathrm{C}$ for $1 \mathrm{~min}$, the epidermal layer was removed and the sample was cut into $3 \times$ 3 -mm pieces and attached to a polypropylene film using double-sided tape. Sample thickness was $150-200 \mu \mathrm{m}$. The depth of analysis was $1.317 \mu \mathrm{m}$ at $650 \mathrm{~cm}^{-1}$ and $0.214 \mu \mathrm{m}$ at $4,000 \mathrm{~cm}^{-1}$. The FTIR spectrum was corrected to compensate for these differences.

The full-thickness skin samples without the fat layer were cut into smaller pieces (approximately $15 \times 15 \mathrm{~mm}$ ) for microscopic observation (skin sectioning)and divided into two groups. One group was treated with plasma jet; the other was not treated. Afterward treatment, the samples were cut and fixed for four days in $10 \%$ neutral buffered formalin containing sodium phosphate monobasic $\left(44-\mathrm{g} \mathrm{NaH}_{2} \mathrm{PO}_{4} \cdot \mathrm{H}_{2} \mathrm{O}\right)$, formaldehyde solution (1- $\mathrm{L} 35 \% \mathrm{CH}_{2} \mathrm{O}$ ), sodium phosphate dibasic anhydrous (65-g $\mathrm{Na}_{2} \mathrm{HPO}_{4}$ ), and distilled water $(9 \mathrm{~L})$. After the four days, the samples were dehydrated and embedded into paraffin molds, sectioned at a thickness of several micrometers using a microtome, and placed on glass slides. To visualize the change in the stratum corneum at microscale, hematoxylin-eosin staining was performed.

\section{RESULTS AND DISCUSSION}

\section{A. Microscopic Observation}

The stratum corneum layer in Fig. 2(a) had an average thickness close to $30 \mu \mathrm{m}$. After $10 \mathrm{~s}$ of plasma jet treatment, the average thickness decreased to about $20 \mu \mathrm{m}$; after 30 $\mathrm{s}$ of treatment, to $18 \mu \mathrm{m}$; and after $60 \mathrm{~s}$ of treatment, $10 \mu \mathrm{m}$ [Fig. 2(b-d), respectively]. Thickness was determined based on an average thickness measured by microscope at 10 different spots. 


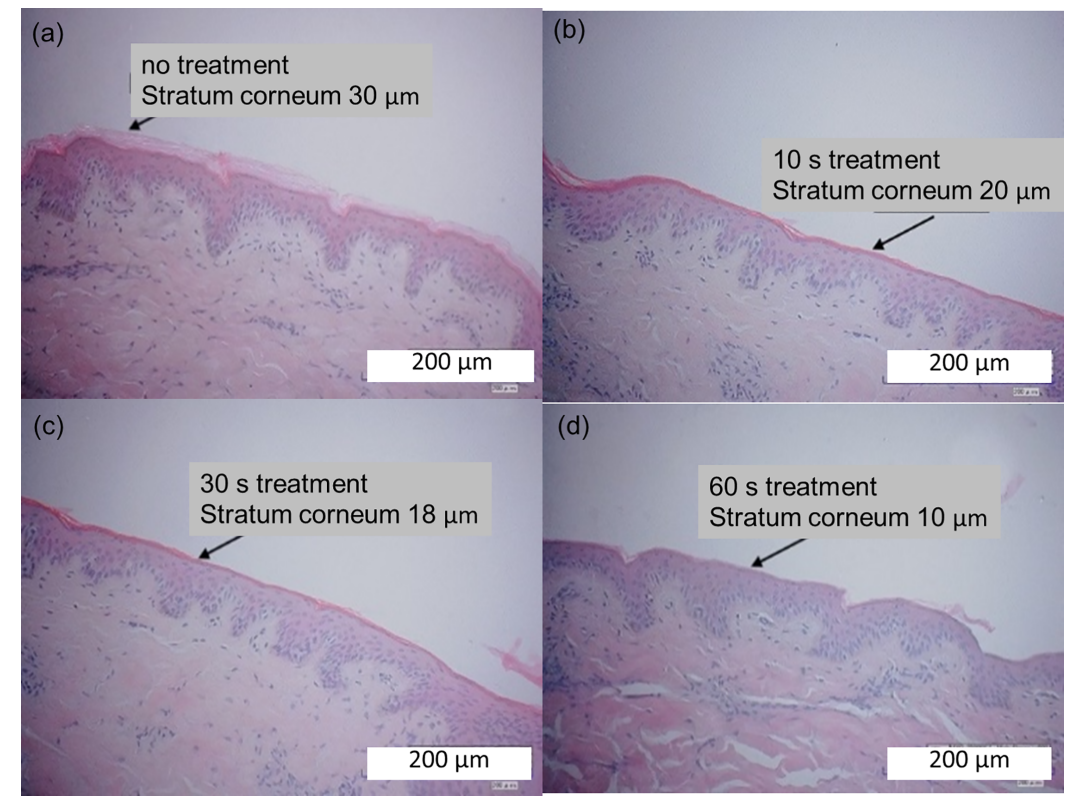

FIG. 2: Histological cross sections of (a) nontreated skin sample, (b) $10 \mathrm{~s}$, (c) $30 \mathrm{~s}$, and (d) $60 \mathrm{~s}$

\section{B. ATR-FTIR Analysis}

There are a several methods of analyzing skin structure and composition. These include Raman spectroscopy, ${ }^{34} \mathrm{X}$-ray diffraction, ${ }^{35}$ electron diffraction, ${ }^{36}$ and transmission electron microscopy. ${ }^{37}$ ATR-FTIR can tell us about skin hydration and about the structures of lipids or proteins. ${ }^{38,39}$

\section{Water $\mathrm{OH}$ Bands}

Figure 3 is a typical ATR-FTIR spectrum of the stratum corneum layer (black line). The spectrum is overlapped by many vibrational bands and the analysis is not simple. An extremely large portion of the spectrum is covered by $\mathrm{OH}$ bands resulting from the liquid water present in the epidermal layer. To subtract these bands, the spectrum of distilled water was measured. The green or water line in Fig. 3 represents the infrared spectrum of the distilled water. The water spectrum was scaled in a such way that after the subtraction, a zero spectrum was obtained in the ranges $1,800-2,000 \mathrm{~cm}^{-1}$ and $3,400-4,000$ $\mathrm{cm}^{-1}$. The resulting spectrum (blue or middle line) was analyzed further.

\section{Methyl $\mathrm{CH}_{3}$ and Methylene $\mathrm{CH}_{2}$ Bands}

The bandwidth and absorbance of the vibrational bands depicted in Fig. 4 were analyzed. Lipids of the stratum corneum were characterized by the methylene symmetric 


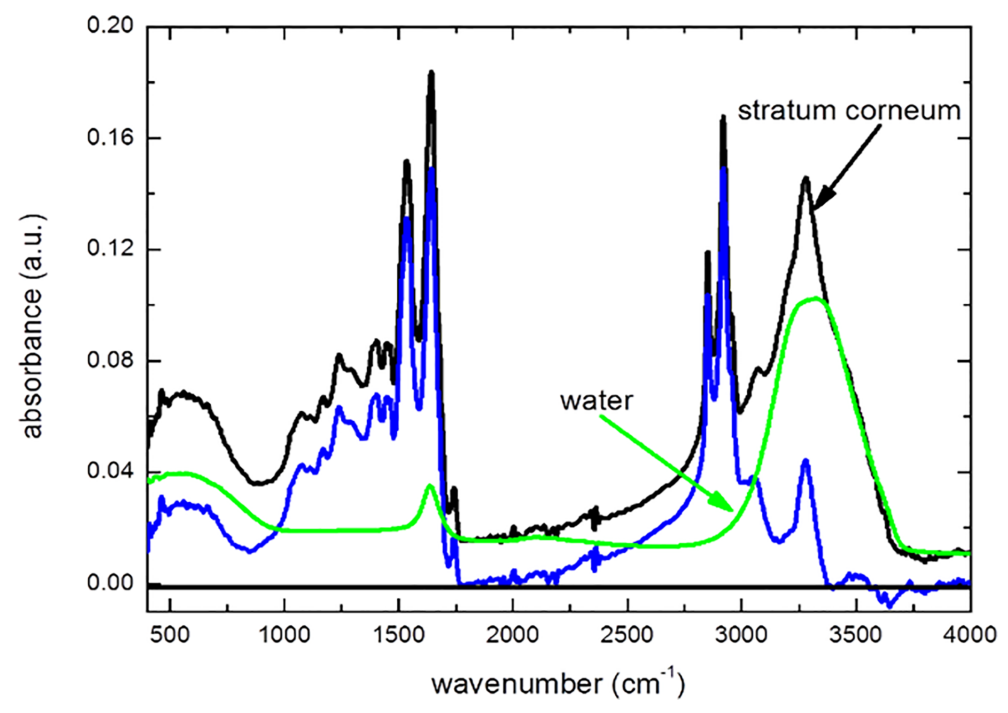

FIG. 3: Spectrum of stratum corneum (black), water (green), and after subtraction of water (blue or middle line)

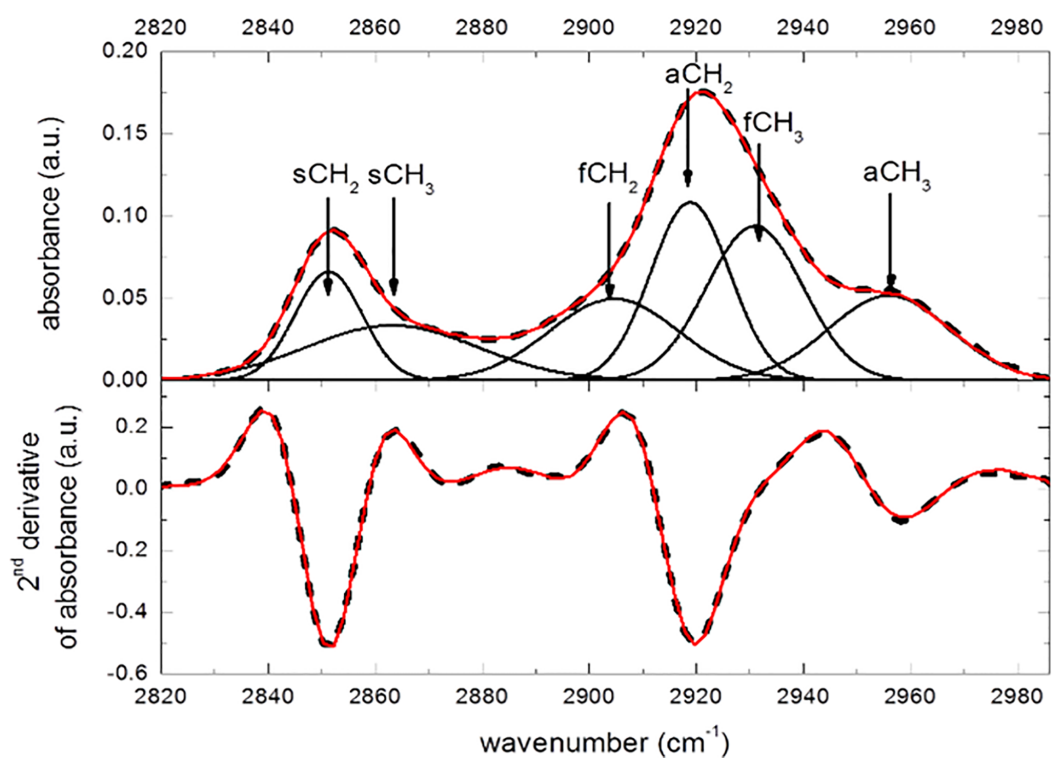

FIG. 4: Symmetric and asymmetric stretch simulation of methyl and methylene, FTIR spectrum (top) and second derivative (bottom). Dotted lines represent experimental spectrum; red or solid line on top of dotted line represents sum of Gaussian fits.

and asymmetric stretches at 2,850 $\mathrm{cm}^{-1}\left(\mathrm{sCH}_{2}\right)$ and 2,920 $\mathrm{cm}^{-1}\left(\mathrm{aCH}_{2}\right)$, and the methyl symmetric stretches at 2,865 $\mathrm{cm}^{-1}\left(\mathrm{sCH}_{3}\right)$ (Fig. 4). The methyl asymmetric stretch 
vibration at 2,955 $\mathrm{cm}^{-1}\left(\mathrm{aCH}_{3}\right)$ came from proteins. The small band at $2,900 \mathrm{~cm}^{-1}\left(\mathrm{fCH}_{2}\right)$ was caused by the Fermi resonance of the $\mathrm{CH}_{2}$ symmetric stretch. The peak centered at $2,930 \mathrm{~cm}^{-1}\left(\mathrm{fCH}_{3}\right)$ was due to the $\mathrm{CH}_{3}$ Fermi resonance. ${ }^{40}$ These bands were fitted by a Gaussian function. To increase the precision of the fit, the second derivative of the spectra was also simulated, scaled to have approximately the same effect on the result as the experimental spectrum (Fig. 4). The absorbance of the methylene symmetric and asymmetric stretches at $2,850 \mathrm{~cm}^{-1}\left(\mathrm{sCH}_{2}\right)$ and $2,920 \mathrm{~cm}^{-1}\left(\mathrm{aCH}_{2}\right)$ can be attributed to the concentration of lipids in the lipid matrix. The bandwidth of a vibration is connected to the structural changes of the lipids. Usually, an increase in bandwidth means an increase in the interaction between functional groups.

\section{Effect of Treatment Time}

The decreases in absorbance in the symmetric and asymmetric methylene stretching bands and in the symmetric methyl stretching band indicate the extraction of lipids, with saturation after $120 \mathrm{~s}$ of the treatment (Fig. 5).

Tsai et al. found that the absorbance of the $\mathrm{CH}_{2}$ asymmetric stretching band correlates with the lipid amount better than the $\mathrm{CH}_{2}$ symmetric stretching band. ${ }^{41}$ However, the ratio of the asymmetric stretches of $\mathrm{CH}_{3}$ and $\mathrm{CH}_{2}$ correlate with the lipid amount in the stratum corneum even better (Fig. $6, \mathrm{aCH}_{2} / \mathrm{aCH}_{3}$ ratio). ${ }^{42}$

Lipids in the stratum corneum are composed of long hydrocarbon chains. The lipid tails consist of $\mathrm{CH}_{2}$ groups with $\mathrm{CH}_{3}$ groups at the end of the chains. As the number of

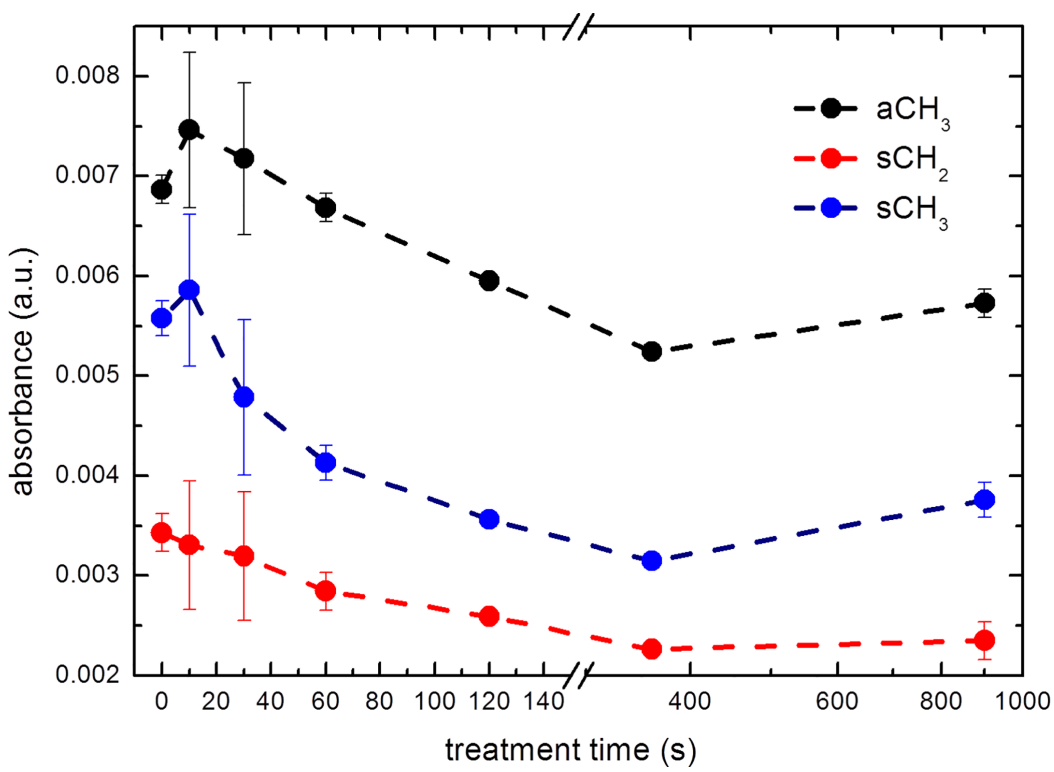

FIG. 5: Symmetric and asymmetric stretches/absorbance of methyl and methylene 


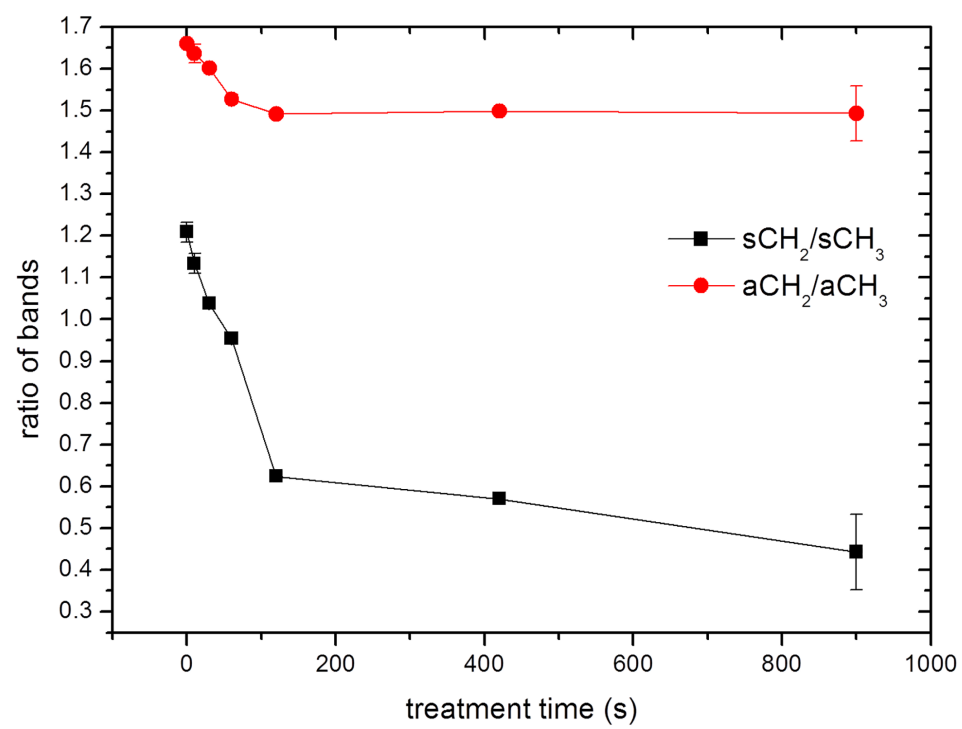

FIG. 6: Ratio of symmetric and asymmetric stretches of methyl and methylene. Ratio $\mathrm{aCH}_{2} /$ $\mathrm{aCH}_{3}$ represents evolution of number of lipids in stratum corneum; $\mathrm{sCH}_{2} / \mathrm{sCH}_{3}$ represents evolution in length of lipid chains or decrease in number of $\mathrm{CH}_{2}$ groups by oxidation.

$\mathrm{CH}_{3}$ functional groups is proportional to the absorbance of the symmetric stretches of $\mathrm{CH}_{3}$, and the number of $\mathrm{CH}_{2}$ functional groups is proportional to the absorbance of the symmetric stretches of $\mathrm{CH}_{2}$, the ratio of these bands can characterize the average length of the lipid chains (Fig. $6, \mathrm{sCH}_{2} / \mathrm{sCH}_{3}$ ratio).

When this ratio changes, the length of the hydrocarbon chain also changes. In our situation, the change in the ratio indicated the breaking of bonds because of the plasma interaction (ions, radicals) with the lipids, or the decreae in $\mathrm{CH}_{2}$ functional groups because of oxidation.

According to Fig. 6, decrease in the number of $\mathrm{CH}_{2}$ functional group and lipid extraction stopped after $120 \mathrm{~s}$ of treatment. The same saturation effect was observed in the bandwidth in the symmetric methylene stretching band (Fig. 7). The bandwidth increased from $16 \mathrm{~cm}^{-1}$ to almost $20 \mathrm{~cm}^{-1}$. This means that the intermolecular interaction between lipid chains increased, suggesting a disturbed lamellar structure.

Plasma's influence results from any of several phenonema, such as temperature, UV radiation, electric field, and presence of ions and radicals. To find out which phenomenon was responsible for changes in the pig skin samples, we investigated separately the effect of temperature and UV radiation.

\section{Temperature Effect}

The rise in temperature of the samples caused by plasma irradiation and hot air flow from the fan during 60-s treatment was measured and compared by a thermal infrared 


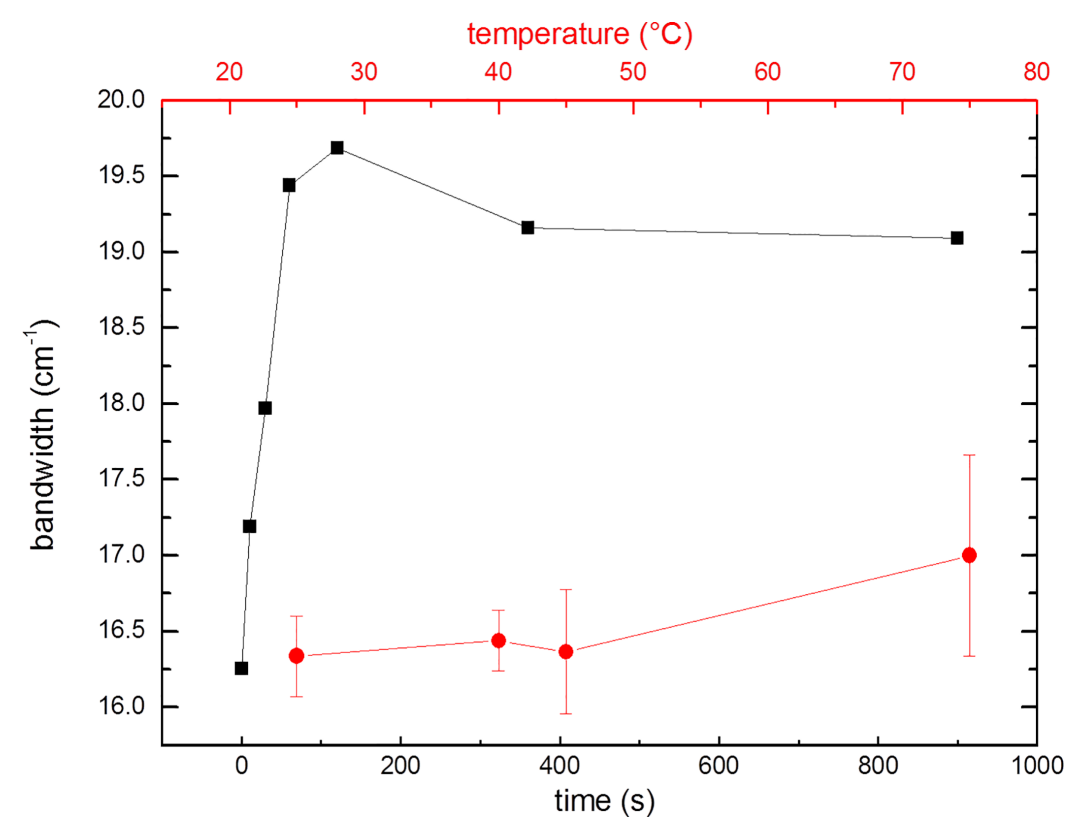

FIG. 7: Dependency of bandwidth of methylene symmetric stretch on treatment time (black square) and on temperature (solid circles)

camera (TVS-200, Avio). The change in temperature is shown in Fig. 8. The hot air flow trials reached maximal temperatures of $40^{\circ} \mathrm{C}, 48^{\circ} \mathrm{C}$, and $75^{\circ} \mathrm{C}$ with decreasing distance while the skin treated by plasma jet coupled with $4 \mathrm{kV}$ reached a maximum temperature of $45^{\circ} \mathrm{C}$ (red open circles in Fig. 8). After plasma treatment, the temperature decreased to the initial value after approximately $100 \mathrm{~s}$. The skin samples were examined via ATRFTIR after the decrease in temperature. Heating can increase the skin's fluidity, which has been demonstrated several times. ${ }^{42,43}$

The structural changes of the stratum corneum lipids occurred between $20^{\circ} \mathrm{C}$ and $40^{\circ} \mathrm{C}$, changing from an orthorhombic to a hexagonal order. ${ }^{44}$ However, as the temperature decreased, the lipid membrane returned to its original state. Figure 7 (solid circles) demonstrates the evolution of the bandwidth of the $\mathrm{CH}_{2}$ symmetric stretching band after treatment with heated air flow at different maximal temperatures. The heat treatment had no influence on bandwidth after the skin cooled. A slight increase was observed at a maximal temperature of $75^{\circ} \mathrm{C}$, but this temperature is not suitable for skin treatment. These results showed that plasma temperature below $45^{\circ} \mathrm{C}$ does not affect the skin significantly.

\section{UV Radiation Effect}

Plasma is a source of radiation generated by excited species. Argon plasma ignited in the air atmosphere emits light in the range of $280-450 \mathrm{~nm}$ by the nitrogen (C-B) second 


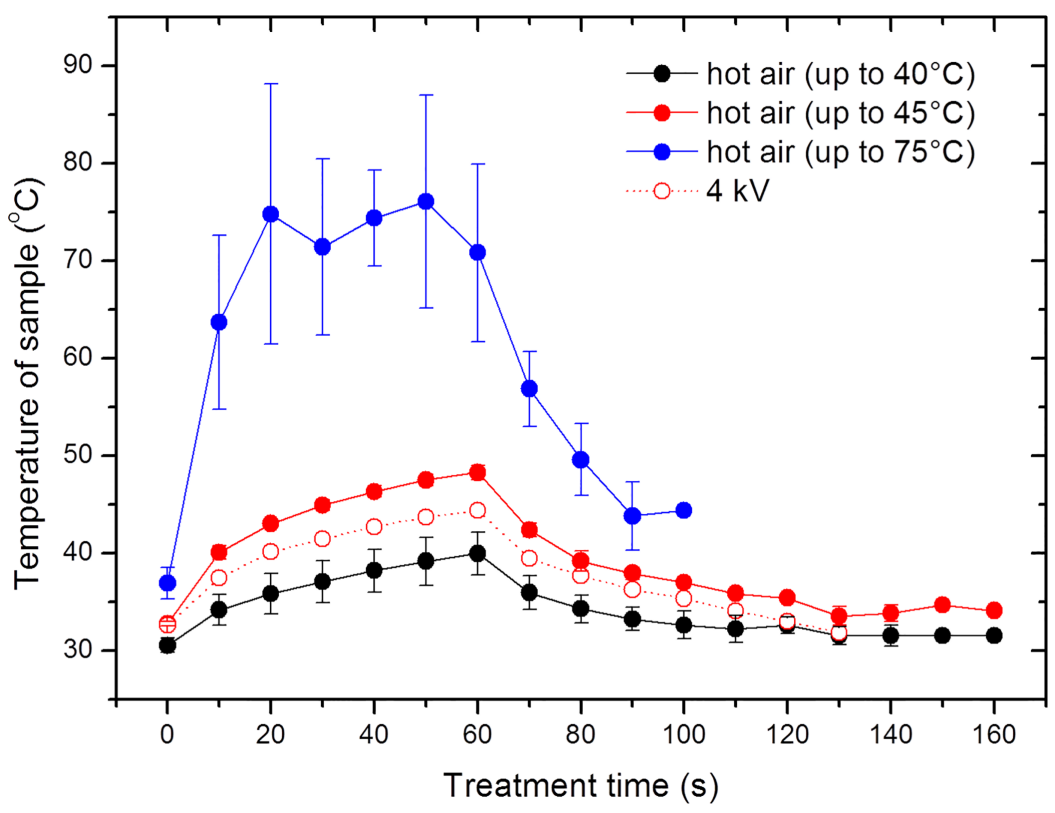

FIG. 8: Evolution of skin during plasma jet treatment (open red circles) and during heating by hot air (solid circles)

positive system, in the range of 306-322 nm by the $\mathrm{OH}(\mathrm{A}-\mathrm{X})$ system, in the range of 190-290 $\mathrm{nm}$ by the NO-gamma (A-X) system, in the range 130-200 $\mathrm{nm}$ by the nitrogen (A-X) LBH system, and at 109 and $126 \mathrm{~nm}$ the first and second continuum of the argon dimer. To investigate the effect of UV radiation, we irradiated the skin samples with plasma jet through a filter. However, emission under $170 \mathrm{~nm}$ was very strongly absorbed by molecular oxygen and partially by nitrogen. Transmittance through the filter materials is shown in Fig. 9. We also used a lamp with an emission of $254 \mathrm{~nm}$ and another lamp with an emission of $365 \mathrm{~nm}$. The irradiation of a sample with visible light should have almost no effect. However, neither UV (through the $\mathrm{BK} 7$ or the $\mathrm{MgF}_{2}$ filter) had any noticeable effect on the structure of the skin lipids after $1 \mathrm{~min}$. In our case, no effect of UV/VUV radiation on the bandwidth of the lipid bands was observed, probably because of the short irradiation duration.

UV radiation can cause the formation of epoxides, hydroxides, hydrogenation of the double bonds, and breaking down of carbon chains. ${ }^{45}$ Mainly fatty acids with double bonds are sensitive to the formation of oxygenated molecules in the presence of oxygen in the air.

The arrangements of stratum corneum lipids and water loss prevention recovered after three days and returned to initial state, thanks to the skin's repair processes. ${ }^{46}$ Trommer et al. ${ }^{47}$ found that the peroxidation of unsaturated fatty acids and cholesterol is limited and not linearly proportional to time because the difference between irradiation by UV at $30 \mathrm{~min}$ and $24 \mathrm{~h}$ was only twofold.

Volume 11, Issue 1, 2021 


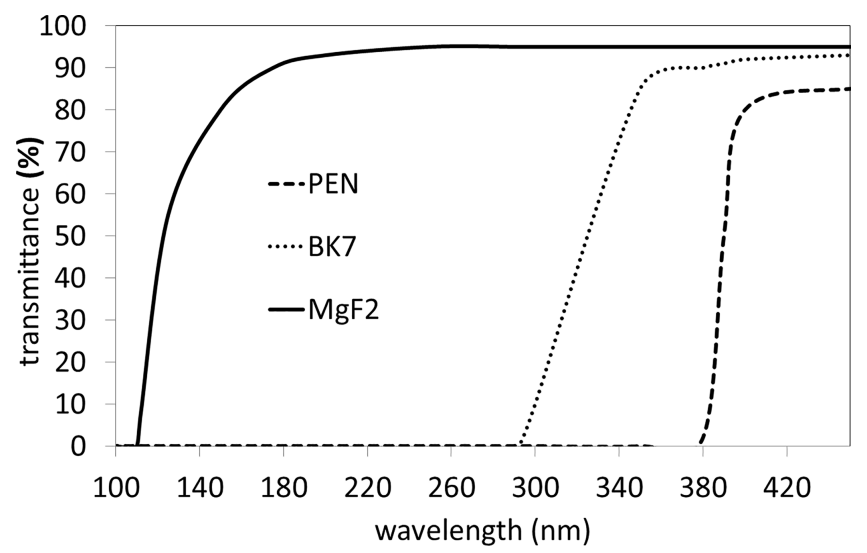

FIG. 9: Transmittance of PEN film, borosilicate glass (BK7), and $\mathrm{MgF}_{2}$ glass used for investigation of UV radiation effects on skin lipids

\section{Posttreatment Behavior}

We observed changes in the symmetric methylene stretching band in the stratum corneum in skin samples after $10 \mathrm{~min}, 1$ day, 2 days, and 5 days after plasma jet treatment (Fig. 10 black and red or everyday treated lines), and in skin samples not treated by plasma jet (Fig. 10 blue or non-treated line). The skin samples treated for 1 min (Fig. 10 black line), and the skin samples treated every day for $1 \mathrm{~min}$ (Fig. 10 red or everyday treated line) were observed. Some delay-induced changes were seen. Points at time zero represent the samples before plasma treatment (Fig. 10 red or everyday treated lines and black lines). Decreasing bandwidth is usually determined by strengthening of the barrier

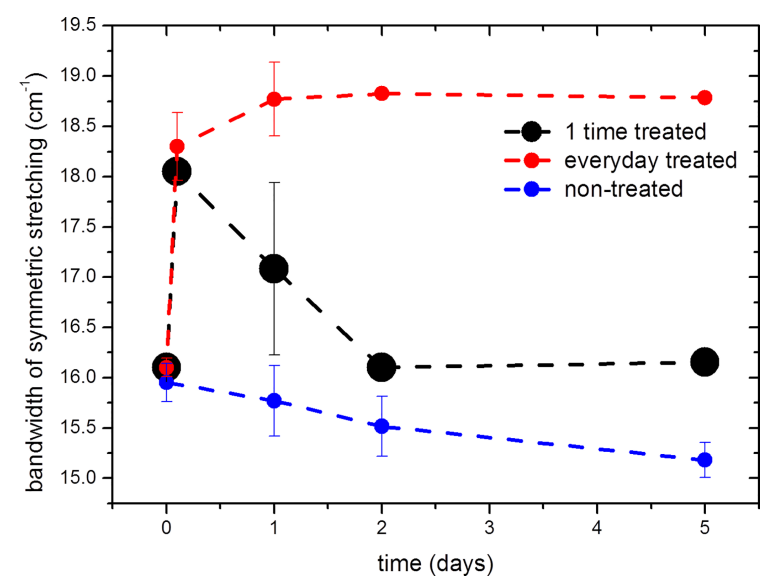

FIG. 10: Bandwidth of symmetric stretching band of $\mathrm{CH}_{2}$ of nontreated skin samples, one-time treated sample and once daily 1-min-treated sample 
properties and vice versa. The nontreated samples showed decreaseing bandwidth (Fig. 10 blue or non-treated line). Because the nontreated skin was stored at the room temperature, this decrease was related to structural changes due skin aging and water loss. If the skin was treated by plasma jet once, the bandwidth increased (from approximately 16 to $18 \mathrm{~cm}^{-1}$ ). After one day, we observed that the lipid membrane returned to the initial state, and by the second day the bandwidth reached initial values. However, when the sample was treated every day for $1 \mathrm{~min}$, the bandwidth was maintained higher for a longer time.

\section{CONCLUSION}

Argon plasma jet treatment of the stratum corneum was investigated using ATR-FTIR. The treatment was applied at $10 \mathrm{~s}$ up to $900 \mathrm{~s}$. Our work focused on the bandwidth and the absorbance of the symmetric and asymmetric stretching $\mathrm{CH}_{2}$ and $\mathrm{CH}_{3}$ bands and their ratios. All of the main changes in the skin occurred up to $120 \mathrm{~s}$; after this time, saturation was observed. We conclude that the decrease in absorbance of the lipid vibrations in the wavenumber range of 2,800-3,000 $\mathrm{cm}^{-1}$ was induced by lipid extraction. The etching of the stratum corneum by plasma jet decreased in thickness from 30 to $10 \mu \mathrm{m}$ in $60 \mathrm{~s}$. The amount of intercellular lipids per layer decreased with increasing depth from the surface of the stratum corneum. Thus, the fractional volume occupied by the corneocytes increased with increasing depth. ${ }^{48-50}$ We observed that UV radiation and temperatures up to $45^{\circ} \mathrm{C}$ did not cause any long-term change in lipid structure, as characterized by the symmetric stretching band of $\mathrm{CH}_{2}$. We conclude that etching, lipid extraction, and structural changes in the lipids were caused by particles present in the plasma such as ions, electrons, metastable particles, or radicals. However, we could not estimate the effect of the electrical field. The increase in bandwidth lasted up to two days. This time could be increased by repeated plasma treatments. Our study of the structural changes in lipids caused by plasma treatment will contribute to improved transdermal drug delivery and identification of the risks of skin sterilization.

\section{REFERENCES}

1. Yadav DK, Adhikari M, Kumar S, Ghimire B, Han I, Kim MH, Choi EH. Cold atmospheric plasma generated reactive species aided inhibitory effects on human melanoma cells: An in vitro and in silico study. Sci Rep. 2020;10:3396.

2. Duan J, Lu X, He G. On the penetration depth of reactive oxygen and nitrogen species generated by a plasma jet through real biological tissue. Physics Plasmas. 2017;24(7):073506.

3. Kos S, Blagus T, Cemazar M, Filipic G, Sersa G, Cvelbar U. Safety aspects of atmospheric pressure helium plasma jet operation on skin: In vivo study on mouse skin. PLoS One. 2017;12(4):e0174966.

4. Hayashida K, Blajan M, Kusamori K, Katsumi H, Yamamoto A, Shimizu K. Basic study of transdermal absorption enhancement by using atmospheric microplasma. 37th International Symposium on Dry Process. Awaji Island, Japan: Awaji Yumebutai International Conference Center; 2015. p. 53.

5. Von WT, Metelmann HR, Weltmann KD. Clinical plasma medicine: State and perspectives of in vivo application of cold atmospheric plasma. Contrib Plasma Physics. 2014;54(2):104-17.

6. Emmert S, Brehmer F, Hänßle H, Helmke A, Mertens N, Ahmed R, Simon D, Wandke D,

Volume 11, Issue 1, 2021 
Maus-Friedrichs W, Däschlein G, Schön MP, Viöl W. Atmospheric pressure plasma in dermatology: Ulcus treatment and much more. Clin Plasma Med. 2013;1:24-9.

7. Lee Y, Ricky S, Lim TH, Jang KS, Kim H, Song Y, Kim SY, Chung K. Wound healing effect of nonthermal atmospheric pressure plasma jet on a rat burn wound model: A preliminary study. J Burn Care Res. 2019;6:923-9.

8. Loesch M, Somani AK, Kingsley M, Travers J, Spandau D. Skin resurfacing procedures: New and emerging options. Clin Cosmet Invest Dermatol. 2014;7:231-41.

9. Busco G, Robert E, Chettouh-Hammas N, Pouvesle JM, Grillon C. The emerging potential of cold atmospheric plasma in skin biology. Free Rad Biol Med. 2020;161:290-304.

10. Vijayarangan V, Delalande A, Dozias S, Pouvesle JM, Robert E, Pichon C. New insights on molecular internalization and drug delivery following plasma jet exposures. Int J Pharm. 2020;119874.

11. Omran AV, Busco G, Ridou L, Dozias S, Grillon C, Pouvesle JM, Robert E. Cold atmospheric single plasma jet for RONS delivery on large biological surfaces. Plasma Sources Sci Technol. 2020;29(10):105002.

12. Shimizu K, Tran AN, Kristof J, Blajan M. Investigation of atmospheric microplasma for improving skin permeability. Proceedings of the 2016 Electrostatics Joint Conference; 2016 Jun 13-16; West Lafayette, Indiana, USA; 2016. p. 13-8.

13. Kalghatgi S, Tsai C, Gray R, Pappas D. Transdermal drug delivery using cold plasmas. 22nd International Symposium on Plasma Chemistry; 2015 July 5-10; Antwerp, Belgium.

14. Shimizu K, Hayashida K, Blajan M. Novel method to improve transdermal drug delivery by atmospheric microplasma irradiation. Biointerphases. 2015;10:029517.

15. Shimizu K, Tran AN, Blajan M. Effect of microplasma irradiation on skin barrier function. Jpn J Appl Phys. 2016;55:07LG01.

16. Kristof J, Miyamoto H, Tran AN, Blajan M, Shimizu K. Feasibility of transdermal delivery of cyclosporine A using plasma discharges. Biointerphases. 2017;12:02B40.

17. Gelker M, Müller-Goymann C, Viöla W. Permeabilization of human stratum corneum and full-thickness skin samples by a direct dielectric barrier discharge. Clin Plasma Med. 2018;9:34-40.

18. Sakudo A, Yagyu Y, Onodera T. Disinfection and sterilization using plasma technology: Fundamentals and future perspectives for biological applications. Int J Mol Sci. 2019;20:5216.

19. Klämpfl TG, Isbary G, Shimizu T, Li YF, Zimmermann JL, Stolz W, Schlegel J, Morfill GE, Schmidt HU. Cold atmospheric air plasma sterilization against spores and other microorganisms of clinical interest. Appl Environ Microbiol. 2012;78:5077-82.

20. Konesky AG, Simeonov SB. Electrosurgical apparatus to generate a dual plasma stream and method thereof. Patent US9681907B2. 2011 Jan 28.

21. Osman I, Ponukumati A, Vargas M, Bhakta D, Ozoglu B, Bailey C. Plasma-activated vapor for sanitization of hands. Plasma Med. 2016;6:235-45.

22. Xie J, Chen Q, Suresh P, Roy S, White JF, Mazzeo AD. Paper-based plasma sanitizers. Proc Natl Acad Sci. 2017;114:5119-24.

23. Baroni A, Buommino E, De Gregorio V, Ruocco E, Ruocco V, Wolf R. Structure and function of the epidermis related to barrier properties. Clin Dermatol. 2012;30:57-262.

24. Das C, Olmsted PD. The physics of stratum corneum lipid membranes. Phil Trans A Math Phys Eng Sci. 2016;374:2015126.

25. Sjövall P, Skedung L, Gregoire S, Biganska O, Clément F, Luengo GS. Imaging the distribution of skin lipids and topically applied compounds in human skin. Sci Rep. 2018;8:16683.

26. Scheuplein RJ, Blank IH. Permeability of the skin. Physiol Rev. 1971;51:702-47.

27. Choi JH, Nam SH, Song YS, Lee HW, Lee HJ, Song K, Hong JW, Kim GC. Treatment with lowtemperature atmospheric pressure plasma enhances cutaneous delivery of epidermal growth factor by regulating E-cadherin-mediated cell junctions. Arch Dermatol Res. 2014;306:635-43.

28. Weber G, Bjerke M, DeSimone D. Integrins and cadherins join forces to form adhesive networks. J Cell Sci. 2011;124:1183-93. 
29. Lee HY, Choi JH, Hong JW, Kim GC, Lee HJ. Comparative study of the Ar and He atmospheric pressure plasmas on E-cadherin protein regulation for plasma-mediated transdermal drug delivery. J Phys D: Appl Phys. 2018;51:215401.

30. Kristof J, Miyamoto H, Blajan M, Shimizu K. Effect of plasma on structure and permeability of epidermal layer of pig skin. Proceedings of the 2018 Electrostatics Joint Conference, Boston, MA. June 2018:G2.

31. Shimizu K, Biological effects and enhancement of percutaneous absorption on skin by atmospheric microplasma irradiation. Plasma Med. 2015;5:205-21.

32. Shimizu K, Tran AN, Hayashida K, Blajan M. Comparison of atmospheric microplasma and plasma jet irradiation for increasing of skin permeability. J Phys D: Appl Physics. 2016;49:315201.

33. Kristof J, Tran AN, Blajan M, Shimizu K. A study of the influence of plasma particles for transdermal drug delivery, recent global research and education: Technological challenges. Adv Intell Sys Comput. 2016;519:167-73.

34. Caspers PJ, Lucassen GW, Wolthuis R, Bruining HA, Puppels GJ. In vitro and in vivo Raman spectroscopy of human skin. Biospectroscopy. 1998;4:S31-8.

35. Bouwstra JA, Gooris GS, Weerheim A, Kempenaar J, Ponec M. Characterization of stratum corneum structure in reconstructed epidermis by X-ray diffraction. J Lipid Res. 1995;36:496-504.

36. Nakazawa H, Imai T, Hatta I, Sakai S, Inoue S, Kato S. Low-flux electron diffraction study for the intercellular lipid organization on a human corneocyte. BBA-Biomembr. 2013;1828:1424-31.

37. Honeywell-Nguyen PL, de Graaff AM, Groenink HWW, Bouwstra JA. The in vivo and in vitro interactions of elastic and rigid vesicles with human skin. BBA-Gen Subjects. 2002;1573:130-40.

38. Karande P, Jain A, Ergun K, Kispersky V, Mitragotri S. Design principles of chemical penetration enhancers for transdermal drug delivery. Proc Natl Acad Sci. 2005;102;4688-93.

39. Boncheva M, Damien F, Normand V. Molecular organization of the lipid matrix in intact Stratum corneum using ATR-FTIR spectroscopy. Biochim Biophys Acta. 2008;1778:1344-55.

40. Wei Z, Jiao D, Xu J. Using Fourier transform infrared spectroscopy to study effects of magnetic field treatment on wheat (Triticum aestivum L.) seedlings. J Spectrosc. 2015;570190.

41. Tsai J-CH, Lo Y-L, Lin CH-Y, Sheu H-M, Lin J-CH. Feasibility of rapid quantitation of stratum corneum lipid content by Fourier transform infrared spectrometry. Spectroscopy. 2004;18:423-31.

42. Petersen KK, Rousing ML, Jensen C, Arendt-Nielsen L, Gazerani P. Effect of local controlled heat on transdermal delivery of nicotine. Int J Physiol Pathophysiol Pharmacol. 2011;3:236-42.

43. Olsztyńska-Janus S, Pietruszka A, Kiełbowicz Z, Czarnecki MA. ATR-IR study of skin components: Lipids, proteins and water. Part I: Temperature effect. Spectrochim Acta A: Mol Biomol Spectrosc. 2018;188:37-49.

44. Mendelsohn R, Flach CR, Moore DJ. Determination of molecular conformation and permeation in skin via IR spectroscopy, microscopy and imaging. Biochim Biophys Acta-Biomembranes. 2006; 1758:923-33.

45. Yousif E, Haddad R. Photodegradation and photostabilization of polymers, especially polystyrene: Review. Springerplus. 2013;2:398.

46. Merle C, Laugel C, Baillet-Guffroy A. UVA or UVB irradiation on cutaneous lipids in films or in solution. Photochem Photobiol. 2010;86:553-62.

47. Trommer H, Wagner J, Graener H, Neubert RH. The examination of skin lipid model systems stressed by ultraviolet irradiation in the presence of transition metal ions. Eur J Pharm Biopharm. 2001;51:207-14.

48. Bommannan D, Potts RO, Guy RH. Examination of stratum corneum barrier function in vivo by infrared spectroscopy. J Invest Dermatol. 1990;95(4):403-8.

49. Mackenzie IC, Linder JE. An examination of cellular organization within the SC by a silver staining method. J Invest Dermatol. 1989(61):245-50.

50. Brody I. A light and electron microscopy study of the normal human stratum corneum with particular reference to the intercellular space. Upsala J Med Sci. 1971;35:247-64.

Volume 11, Issue 1, 2021 
